\title{
Seafloor Stereo Map of Coastal Areas for Geomorphological Studies
}

\author{
Hideaki Goto ${ }^{\mathrm{a}}$ * \\ ${ }^{a}$ Department of Geography, Hiroshima University, hgoto@hiroshima-u.ac.jp \\ * Corresponding author
}

Keywords: digital elevation model (DEM), 3-D, Anaglyph, submerged terrace, Okinawa

\begin{abstract}
:
Topographical anaglyph maps produced from digital elevation model (DEM) are an easy and practical means of inland topography and seafloor observations (Goto, 2016). Since the 2000s, several coastal DEMs surveyed by multi-beam sound systems have been stored, though submarine topographic features have been popularly represented by contour lines in the previous century. Various DEM-based visual maps including shaded relief or stereo maps with contour lines have been adapted to observe inland topography (Awata, 2017); however, they have been rarely used to express slope shade with contour lines in coastal areas.
\end{abstract}

Since the development of submarine topography above $-120 \mathrm{~m}$ has become relevant for sea-level changes after the last glacial age, deep-sea features such as cliffs and terraces could provide essential information on topographical evolution and crustal movement. Therefore, we produced a stereo image map of slope shade and contour lines in a coastal area based on DEM. Although Louis Ducas du Hauron patented the original idea of producing anaglyphs in 1891(Waker and Dodge, 2001), anaglyph seafloor maps expressing slope shade and contour lines from DEM are new as well as are effective for understanding the geomorphic features of submerged terraces and the broad deformation of the oceanic bed because they enable us to identify small topographic features, such as submerged coral crests and height differences in the wide area.

We studied the area around Inazejima and Iheyajima islands distributed in the north of Okinawa prefecture, southwest Japan. We found it difficult to understand the active tectonics of Nansei-Shoto arc based on only the isolated small islands; thus, we focused on the submerged marine terraces widely developed around these islands to reveal the depth distribution of paleo-shorelines.

The Japan Coast Gard (JCG) conducted a multi-beam survey along the northwestern coast of Okinawa island from 2008 to 2012 (Yasuhara, 2013). The JAMSTEC (2016) stored and disseminated information for the rock and sediment core samples as well as the results of the multi-beam survey on their website, "Data and Sample Research System for Whole Cruise Information in JAMSTEC." We retrieved these data from the JCG and JAMSTEC to generate 1.44-smesh (approximately $44 \mathrm{~m}$ ) and 2-s-mesh (approximately $65 \mathrm{~m}$ ) seafloor DEMs, respectively. We combined these DEMs with a 500-m-mesh DEM (J-EGG500) published by JCG, which were subsequently overlapped in a decreasing resolution. We imported these seafloor DEMs into Simple DEM Viewer ${ }^{\circledR}$ to produce an anaglyph map that was overlapped onto the black and white slope shading base map and contour lines for stereoscopic analysis with red-cyan glasses.

Interpretation of the map revealed that the several submerged marine terraces were distributed around the islands, and the NWW-trending active faults cut and deformed these terraces in the southwest off the coast of Izena island. Stereoscopic analysis with contour lines enabled us to obtain the height difference of the submerged terraces between the west and east sides of Iheya island, which were estimated to have formed during the last glacial age based on the terrace platform depth.

\section{References}

Awata, Y., 2017, Visualization of high-resolution DEMs using stereo contour and relief maps, Annual report on active fault and paleoearthquake researches, No.17, pp.117-136.

Goto, H., 2016, Extensive Area Map of Topographic anaglyphs covering inland and seafloor from detailed digital elevation model for identifying broad tectonic deformation, In Earthquakes, Tsunamis and Nuclear Risks: Prediction and Assessment Beyond the Fukushima Accident, Kamae, K Ed., Springer, Tokyo, Japan, pp.65-74

Japan Agency for Marine-Earth Science and Technology (JAMSTEC), 2016, Data and Sample Research System for Whole Cruise Information in JAMSTEC. 2016, http://www.godac.jamstec.go.jp/darwin/

Yasuhara, T., 2013, Preliminary report on the bathymetric surveys along the northwestern coast of Okinawa Island, Report of Hydrographic and Oceanographic Researches, No.50, pp.80-83 
Waker, B.K. and Dodge, R.E., 2001, 3-D Visualization of Coral Reef Habitat, Nova Southeastern University Oceanographic Center Currents Vol. XV, 4, pp. 4-5, http://works.bepress.com/brian_k_walker/47 